\title{
Setting Times of Portland Cement Blended with Locust Bean Pod and Eggshell Ashes
}

\author{
Olubajo Olumide Olu ${ }^{1, *}$, Osha Odey Ade ${ }^{2}$, Abubakar Jibril ${ }^{1}$ \\ ${ }^{1}$ Department of Chemical Engineering, Faculty of Engineering, Abubakar Tafawa Balewa University, Bauchi, Nigeria \\ ${ }^{2}$ Department of Chemical Engineering, Faculty of Engineering, University of Calabar, Rivers, Nigeria
}

Email address:

ooolubajo@atbu.edu.ng(O.O.Olubajo),oshaodee@gmail.com(O.O.Ade), abujibrilbuu@gmail.com(A. Jibril)

*Corresponding author

\section{To cite this article:}

Olubajo Olumide Olu, Osha Odey Ade, Abubakar Jibril. Setting Times of Portland Cement Blended with Locust Bean Pod and Eggshell Ashes. American Journal of Chemical Engineering. Vol. 8, No. 5, 2020, pp. 103-11. doi: 10.11648/j.ajche.20200805.11

Received: September 2, 2020; Accepted: September 18, 2020; Published: September 28, 2020

\begin{abstract}
This paper investigates the potentials of replacing cement with Locust beans pod ash (LBPA) and Eggshell ash (ESA) on the setting time properties of cement blends such as consistency and initial and final setting times. It also covers a comparative analysis on consistency and setting time results of the cement blends and control. The consistency and setting times of control and twenty-eight (28) cement blends were conducted via Vicat apparatus and Toniest machine respectively according to ASTM standards. The locust bean pod and eggshell powder were calcined at $850^{\circ} \mathrm{C}$ and $500^{\circ} \mathrm{C}$ for 1 hour respectively to obtain the LBPA and ESA. Results indicated a variation in the water consistencies of cement blended with either/both ashes at various LBPA/LBPA-ESA ratios as cement replacement was increased from 0-10 wt.\%. The increase in the water consistencies could be attributed to the diminution of $\mathrm{C}_{3} \mathrm{~S}$ in cement, the unburnt carbon present in the ashes coupled with the porous nature of LBPA and narrower particle size distributions of the cement blends. Whereas, the decrease in the water consistency could be linked with wider particle size distribution. The initial setting times of LBPA cement blends experienced a series of retardations and acceleration while the final setting time experienced a series of accelerations and elongations as the cement replacement was increased. On the other hand, as the cement replacement level was increased, the initial and final setting time of ESA cement blends experienced a retardation followed by accelerations and a series of accelerations and retardations respectively. Similarly, the replacement of ESA with LBPA at various cement replacement led to a variation in both setting times (series of accelerations and retardations) of cement blends. The retardation in the setting times could be linked to the diminution of clinker content or formation of magnesium hydroxide $\mathrm{Mg}(\mathrm{OH})_{2}$, the presence of unburnt carbon in ashes and narrower particle size distribution of the cement blends while the acceleration of the setting times are related to interaction between tricalcium aluminate and limestone to favor ettringite at the expense of monosulfate and a wider particle size distribution of the cement blends. Most of the setting time results for cement blends except 7.5 and $10 \mathrm{wt} . \%$ LBPA cement blends were higher than control and all the cement blends were found to fall within standards for various applications.
\end{abstract}

Keywords: Locust Bean Pod Ash, Eggshell Ash, Consistency, Setting Time, Cement Blends

\section{Introduction}

One of the factors militating against affordable housing in Nigeria is the high cost of cement and the problem of accommodation and inadequate housing is fast becoming a major concern since it is man's basic need [1]. Researches indicate that majority of Nigerian housing units are constructed with concrete in which cement is an essential constituent. Disposal issues are general menace faced by many societies and one way of addressing it, is through the use of biomass such as ESA and LBPA which could be employed as a cement partial replacement material to evaluate their potentials of influencing the setting times and water requirement. Thus, owing to the large disposal of eggshells and locust bean pods has prompted the need convert waste to wealth. The setting time is influenced by several factors such as cement composition, water cementitious material ratio, temperature and supplementary cementitious material [2]. Setting time refers to the degree of stiffness of cement mixture 
to resist penetration of weighted test needle. The significance of the setting time characteristics of cement blends can assist in scheduling the various operations such as transporting, placing and compacting [3]. Setting time is one of the methods employed in determining the quality of cement and its initial and final setting time can be achieved via either a Vicat apparatus or Toniest machine. This setting time determines the rate of hydration of cement samples and can be either accelerated or retarded by the inclusion of supplementary cementitious materials SCMs. Ashes from calcined agricultural wastes such as rice husk ash, coal bottom ash, fly ash, groundnut shell ash, eggshell ash and other biomasses are mostly rich in amorphous silica. The inclusion of these biomasses is evident when concrete or mortar are being transported long distances to where they are to be employed for various construction works.

The locust bean pods are waste obtained from the African locust bean tree "Parkiabiglobosa" which is a perennial legume tree and grows in the savannah zone of West Africa [4, 5] with the pulp separated from the pod and burnt to obtain LBPA. Numerous researchers have employed several materials as substitute for cement such as palm oil husk ash (POHA), pulverized fly ash (PFA) [6], rice husk ash (RHA) [7], coconut husk ash (CHA) [8], eggshell powder ash [9, 10], locust bean pod ash [10] and etc. with various successes. Akpenpuun et al. [11] investigated the effect of replacing LBPA on the setting times and observed that as the LBPA content increased up to $30 \%$, the initial and final setting time experienced a retardation by $66.8 \%$ and $39.7 \%$ respectively. The concrete mix workability diminished as the LBPA content was increased. The enhanced compressive strength of $15 \%$ LBPA cement blend agreed with results from SEM, EDS and XRD which indicated a pronounced presence of CSH gel compared to other samples. They suggested that the crystalline or amorphous nature of the LBPA influenced the setting time which was dependent on the process conditions for obtaining the ash.

Fazeera et al. [9] carried out a feasibility on potentials of ESA on the setting time of several cement blends between $0-2.5 \%$ at interval of $0.5 \%$ and results indicated an acceleration in the setting time of ESA cement compared to control while the percentage rate of reduction of the setting time increase simultaneously. According to Kumar et al. [12], the workability of the mix with ESA obtained by burning eggshells at $800^{\circ} \mathrm{C}$ was observed to diminish as the ESA content was increased from $0-40$ wt. $\%$ at interval of 5 wt.\% due to water absorption effect of the ESA as the water consistency increased from $0.40-0.80$. Balamurugan et al. [13] investigated the use of ESA obtained from burning at $500^{\circ} \mathrm{C}$ on the properties of cement and observed that the initial and final setting time of cement blended with ESA experienced an acceleration by $60.61 \%$ and $48.77 \%$ as the ESA content was increased between 1-5\%. Cement blended with ESA from 0 $2.5 \%$ sets faster than cement paste (decrease the setting time) according to Mtallib and Rabiu [14]. Most research works indicated that the setting times of LBPA and ESA cement blends satisfied the requirement of less than 45 minutes and not greater than $10 \mathrm{hrs}$ [15]. This work tries to investigates the effect of replacing eggshell ash with locust bean pod ash on the water consistency and setting time of various cement blends at various cement replacements from $0-10$ wt. $\%$ at interval of 2.5 wt. $\%$.

\section{Materials and Method}

\subsection{Materials}

Supaset cement CEM II A-L conforms to the NIS 444 [16] obtained from Ashaka cement Ltd., Gombe state. Eggshells were collected from chick hatcheries, bakeries and fast food joints and restaurants. The eggshell ash (ESA) was prepared by burning fowls' eggshells at a temperature of $500^{\circ} \mathrm{C}$ for 1 hour to obtain a complete ash while locust bean pods (LBP) were collected from Badabdi community, Gombe state, Nigeria. The distilled water was employed for mortar preparation and a well quantifiable amount for paste preparation. Water was needed for the hydration reaction of cement and also to make it workable during mixing. Table 1 indicates the chemical composition of OPC, LBPA and ESA.

\subsection{Procedure}

The locust bean pods were dried under the sun for a period of three days, crushed to about $0.5 \mathrm{~mm}$ size using the jaw crusher and then burnt locally using charcoal burner though the pod was not allowed to make contact with the charcoal. Ten grams (10g) of the initially burnt locust bean sample was weighed and then placed in an electric furnace and calcined at $800^{\circ} \mathrm{C}, 850^{\circ} \mathrm{C} \& 900^{\circ} \mathrm{C}$ for 1 hour \& 2 hours respectively to obtain the optimum temperature and time. Eggshells were also obtained from bakeries, sorted, sun dried and ground with a mortar and pestle. The ground eggshell powder was then calcined at a temperature of $500^{\circ} \mathrm{C}$ at $1 \mathrm{hr}$. The resultant ashes from the calcination of the locust bean and eggshell powder were analyzed via a fused bead machine for the oxide analysis and presented in Table 1 [10]. The LBPA ash content was purely obtained and the percentage loss was calculated for each of the heated samples and the optimum condition was determined at $850^{\circ} \mathrm{C}$ for 1 -hour [10]. Table 2 presents the chemical composition of the various locust bean pod ash calcined at 800,850 and $900^{\circ} \mathrm{C}$ at 1 and 2 hours respectively. The consistency test was carried out in accordance with IS 4031 [17] using the Vicat apparatus with plunger as shown in Figure 2 (a). The test permits the Vicat plunger with length of about 40 to $50 \mathrm{~mm}$ to penetrate to a point $5-7 \mathrm{~mm}$ from the bottom of the Vicat mould. Cement paste of standard consistence has a specified resistance to penetration by standard plunger and the water required for such a paste is determined by trial penetrations of pastes with different water contents.

The initial and final setting time of the various cement blends were determined using the automatic Vicat (Toniest) machine with steel needle in accordance with BS 4550 [18] or IS 4031 [19] as shown in Figure 2 (b). The setting time was determined by observing the penetration of needle into cement 
paste of standard consistence until it reaches a specified value where the initial and final setting times in minutes were recorded.

\subsection{Experimental Design Mix}

The experimental matrix for LBPA-ESA cement blends with cement replacements between $0-10 \mathrm{wt} . \%$ is presented in Table 2. The water consistency and setting time were determined comprising of ESA of 2.5, 5, 7.5 and 10 wt.\% which was gradually replaced with LBPA for different mixes.

Table 1. Chemical composition of Portland Cement, LBPA and ESA.

\begin{tabular}{llll}
\hline Oxides & OPC wt.\% & LBPA wt.\% & ESA wt.\% \\
\hline $\mathrm{SiO}_{2}$ & 23.87 & 9.48 & 0.19 \\
$\mathrm{Al}_{2} \mathrm{O}_{3}$ & 7.87 & 2.00 & 0.54 \\
$\mathrm{Fe}_{2} \mathrm{O}_{3}$ & 3.94 & 18.94 & 0.34 \\
$\mathrm{CaO}$ & 57.34 & 19.42 & 49.58 \\
$\mathrm{MgO}$ & 1.76 & 5.95 & 0.82 \\
$\mathrm{SO}_{3}$ & 1.05 & 0.70 & 0.51 \\
$\mathrm{~K}_{2} \mathrm{O}$ & 0.00 & 27.54 & 0.40 \\
$\mathrm{Na}_{2} \mathrm{O}$ & 0.36 & 0.44 & - \\
$\mathrm{P}_{2} \mathrm{O}_{5}$ & - & 7.71 & - \\
$\mathrm{Mn}_{2} \mathrm{O}_{3}$ & - & 0.29 & - \\
$\mathrm{TiO}_{2}$ & - & 0.15 & - \\
$\mathrm{Cl}$ & - & 0.02 & - \\
$\mathrm{Cr}$ & - & 0.04 & - \\
$\mathrm{SrO}$ & - & 0.14 & - \\
$\mathrm{LOI}$ & 3.81 & 7.19 & 47.62 \\
$\mathrm{Sum}$ of Conc. & 100.00 & 100.00 & 100.00 \\
\hline
\end{tabular}

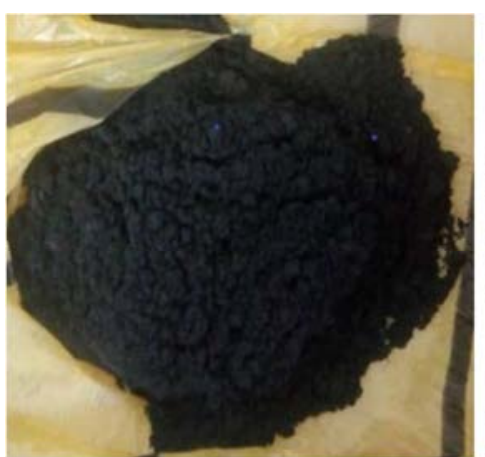

(a)

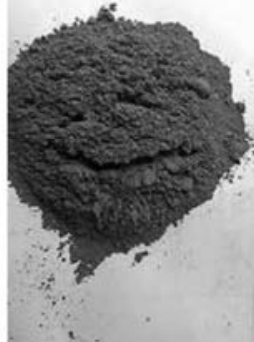

(b)
Figure 1. Locust bean pod ash and Eggshell ash.

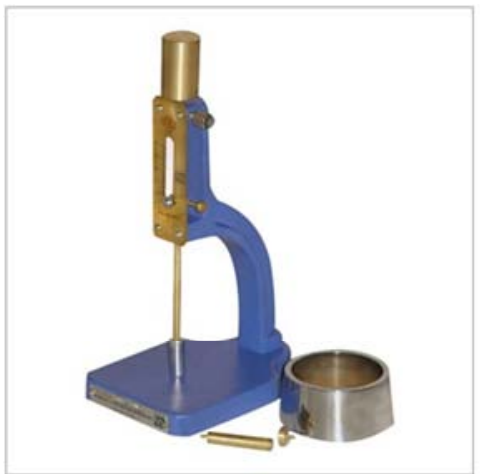

(a)

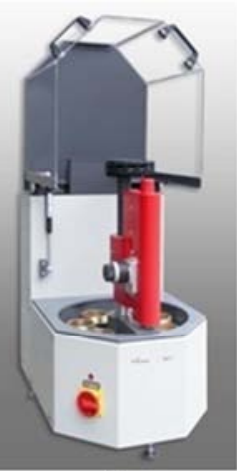

(b)
Figure 2. Vicat apparatus and Toniest machine.

Table 2. Experimental Matrix for control \& cement blended with LBPA \& ESA.

\begin{tabular}{|c|c|c|c|c|c|}
\hline S/No & Cement Blends & LBPA/ LBPA-ESP ratio & $\operatorname{ESA}(g)$ & LBPA (g) & OPC (g) \\
\hline 1 & 100 PC -0 ESA - 0 LBPA & 0 & 0 & 0 & 500 \\
\hline 2 & 97.5 PC-2.5ESA-0 LBPA & 0 & 12.5 & 0 & 487.5 \\
\hline 3 & 97.5 PC-2 ESA-0.5 LBPA & 0.2 & 10 & 2.5 & 487.5 \\
\hline 4 & 97.5 PC-1.5 ESA-1 LBPA & 0.4 & 7.5 & 5 & 487.5 \\
\hline 5 & 97.5 PC-1.25 ESA-1.25 LBPA & 0.5 & 6.25 & 6.25 & 487.5 \\
\hline 6 & 97.5 PC-1 ESA-1.5 LBPA & 0.6 & 5 & 7.5 & 487.5 \\
\hline 7 & 97.5 PC-0.5 ESA - 2 LBPA & 0.8 & 2.5 & 10 & 487.5 \\
\hline 8 & 97.5 PC -0 ESA-2.5 LBPA & 1.0 & 0 & 12.5 & 487.5 \\
\hline 9 & 95 PC- 5 ESA - 0 LBPA & 0 & 25 & 0 & 475 \\
\hline 10 & 95 PC-4 ESA-1 LBPA & 0.2 & 20 & 5 & 475 \\
\hline 11 & 95 PC -3 ESA - 2 LBPA & 0.4 & 15 & 10 & 475 \\
\hline 12 & 95 PC- 2.5 ESA-2.5 LBPA & 0.5 & 12.5 & 12.5 & 475 \\
\hline 13 & 95 PC -2 ESA -3 LBPA & 0.6 & 10 & 15 & 475 \\
\hline 14 & 95 PC-1 ESA- 4 LBPA & 0.8 & 5 & 20 & 475 \\
\hline 15 & 95 PC- 0 ESA-5 LBPA & 1.0 & 0 & 25 & 475 \\
\hline 16 & 92.5 PC-7.5 ESA- 0 LBPA & 0 & 37.5 & 0 & 462.5 \\
\hline 17 & 92.5 PC- 6 ESA- 1.5 LBPA & 0.2 & 30 & 7.5 & 462.5 \\
\hline 18 & 92.5 PC- 4.5 ESA- 3 LBPA & 0.4 & 22.5 & 15 & 462.5 \\
\hline 19 & 92.5 PC-3.75 ESA-3.75 LBPA & 0.5 & 18.75 & 18.75 & 462.5 \\
\hline 20 & 92.5 PC- 3 ESA-4.5 LBPA & 0.6 & 15 & 22.5 & 462.5 \\
\hline 21 & 92.5 PC-1.5 ESA-6 LBPA & 0.8 & 7.5 & 30 & 462.5 \\
\hline 22 & 92.5 PC-0 ESA- 7.5 LBPA & 1.0 & 0 & 37.5 & 462.5 \\
\hline 23 & 90 PC- 10 ESA- 0 LBPA & 0 & 50 & 0 & 450 \\
\hline 24 & 90 PC- 8 ESA-2 LBPA & 0.2 & 40 & 10 & 450 \\
\hline 25 & 90 PC- 6 ESA-4 LBPA & 0.4 & 30 & 20 & 450 \\
\hline 26 & 90 PC-5 ESA-5 LBPA & 0.5 & 25 & 25 & 450 \\
\hline 27 & 90 PC-4 ESA-6 LBPA & 0.6 & 20 & 30 & 450 \\
\hline 28 & 90 PC-2 ESA- 8 LBPA & 0.8 & 10 & 40 & 450 \\
\hline 29 & 90 PC- 0 ESA-10 LBPA & 1.0 & 0 & 50 & 450 \\
\hline
\end{tabular}




\section{Results and Discussion}

\subsection{Chemical Composition of the Starting Materials}

The chemical composition of OPC, LBPA and ESA were tabulated in Table 1 were obtained via X-ray Fluorescence Spectrometer and results revealed that CEM II A - L $42.5 \mathrm{~N}$ had a percentage of reactive silicates content of $23.87 \mathrm{wt} . \%$ while LBPA compositional analysis indicates that it belongs to a class of pozzolanic materials which satisfy most requirements specified by ASTM C618 [20] such as $\mathrm{SO}_{3}$ content of $0.7 \mathrm{wt} . \%$ which should be less than the maximum of 5 wt. $\%$ and LOI of 7.12 wt.\%, except that it has a $\mathrm{SiO}_{2}+\mathrm{Al}_{2} \mathrm{O}_{3}$
$+\mathrm{Fe}_{2} \mathrm{O}_{3}$ which is less than 50 wt.\% with a $\mathrm{CaO}$ content of 19.42 wt. \% which is within the range of $10-30$ wt. $\% \mathrm{CaO}$ thus, Class $\mathrm{C}$ pozzolan. Ikumapayi. [21] obtained a lower $\mathrm{SiO}_{2}+$ $\mathrm{Al}_{2} \mathrm{O}_{3}+\mathrm{Fe}_{2} \mathrm{O}_{3}$ content of 25 wt. $\%$ for LBPA compared with Olubajo et al. [10]. The calcined eggshell (ESA) reveals a high amount of $\mathrm{CaO}$ of 49.58 wt.\% $\left(\mathrm{CaCO}_{3} 88.49\right.$ wt.\%) together with minute quantities of $\mathrm{SiO}_{2}, \mathrm{Al}_{2} \mathrm{O}_{3}, \mathrm{Fe}_{2} \mathrm{O}_{3}, \mathrm{MgO}, \mathrm{SO}_{3}, \mathrm{~K}_{2} \mathrm{O}$ and $\mathrm{Na}_{2} \mathrm{O}$ below 1 wt.\% and a LOI of 47.62 wt.\%. Table 3 presents some determined physical properties of the cement CEM II A-L $42.5 \mathrm{~N}$ while the consistency and setting times of the control specimen and 28 cement blends at various compositions were determined and presented in Table 4.

Table 3. Physical properties of control sample (CEM II A-L 42.5N).

\begin{tabular}{|c|c|c|c|}
\hline Properties & & & \\
\hline Setting time (mins) & 117 & Final setting time & 186 \\
\hline Water consistency $(\%)$ & 29 & & \\
\hline Curing age & 2 days & 7 days & 28 days \\
\hline Compressive Strength $\left(\mathrm{N} / \mathrm{mm}^{2}\right)$ & 23.84 & 38.99 & 48.18 \\
\hline Flexural Strength $\left(\mathrm{N} / \mathrm{mm}^{2}\right)$ & 4.46 & 6.13 & 6.80 \\
\hline
\end{tabular}

Table 4. Setting times and consistency results of various cement blends.

\begin{tabular}{|c|c|c|c|c|c|}
\hline S/No & Cement Blends & LBPA/ LBPA-ESP ratio & Initial/ Final setting time Mins & Water demand mm & Water consistency \% \\
\hline 1 & $100 \mathrm{PC}-0 \mathrm{ESA}-0 \mathrm{LBPA}$ & 0 & $117 / 186$ & 145 & 29.00 \\
\hline 2 & 97.5 PC-2.5ESA-0 LBPA & 0 & $140 / 180$ & 146 & 29.20 \\
\hline 3 & 97.5 PC-2 ESA-0.5 LBPA & 0.2 & $134 / 175$ & 149 & 29.80 \\
\hline 4 & 97.5 PC-1.5 ESA-1 LBPA & 0.4 & $151 / 178$ & 148 & 29.60 \\
\hline 5 & 97.5 PC-1.25 ESA-1.25 LBPA & 0.5 & $190 / 220$ & 152 & 30.40 \\
\hline 6 & 97.5 PC-1 ESA-1.5 LBPA & 0.6 & $168 / 202$ & 169 & 33.80 \\
\hline 8 & 97.5 PC - 0 ESA-2.5 LBPA & 1.0 & $121 / 171$ & 152 & 30.40 \\
\hline 9 & 95 PC-5 ESA - 0 LBPA & 0 & $231 / 285$ & 161 & 32.20 \\
\hline 10 & 95 PC-4 ESA-1 LBPA & 0.2 & $224 / 253$ & 157 & 31.40 \\
\hline 11 & 95 PC -3 ESA - 2 LBPA & 0.4 & $85 / 186$ & 148 & 29.60 \\
\hline 12 & 95 PC- 2.5 ESA-2.5 LBPA & 0.5 & $327 / 386$ & 146 & 29.20 \\
\hline 13 & 95 PC- 2 ESA - 3 LBPA & 0.6 & $164 / 218$ & 155 & 31.00 \\
\hline 15 & 95 PC- 0 ESA-5 LBPA & 1.0 & $77 / 300$ & 152 & 30.40 \\
\hline 16 & 92.5 PC-7.5 ESA- 0 LBPA & 0 & $192 / 251$ & 161 & 32.20 \\
\hline 17 & 92.5 PC- 6 ESA- $1.5 \mathrm{LBPA}$ & 0.2 & $120 / 158$ & 162 & 32.40 \\
\hline 18 & 92.5 PC- 4.5 ESA- 3 LBPA & 0.4 & $121 / 171$ & 153 & 30.60 \\
\hline 19 & 92.5 PC-3.75 ESA-3.75 LBPA & 0.5 & $247 / 333$ & 159 & 31.72 \\
\hline 20 & 92.5 PC- 3 ESA-4.5 LBPA & 0.6 & $179 / 201$ & 159 & 31.78 \\
\hline 21 & 92.5 PC-1.5 ESA-6 LBPA & 0.8 & $117 / 186$ & 162 & 32.40 \\
\hline 22 & 92.5 PC-0 ESA- 7.5 LBPA & 1.0 & $148 / 191$ & 158 & 31.60 \\
\hline 23 & 90 PC- 10 ESA- 0 LBPA & 0 & $156 / 191$ & 155 & 31.00 \\
\hline 24 & 90 PC- 8 ESA-2 LBPA & 0.2 & $124 / 158$ & 158 & 31.60 \\
\hline 25 & 90 PC- 6 ESA-4 LBPA & 0.4 & $120 / 158$ & 162 & 32.40 \\
\hline 26 & 90 PC-5 ESA-5 LBPA & 0.5 & $179 / 201$ & 151 & 30.20 \\
\hline 27 & 90 PC-4 ESA-6 LBPA & 0.6 & $132 / 152$ & 153 & 30.60 \\
\hline 28 & 90 PC-2 ESA- 8 LBPA & 0.8 & $124 / 175$ & 155 & 31.00 \\
\hline
\end{tabular}

\subsection{Effect of Cement Replacement on the Water Consistency of LBPA and ESA Cement Blends}

Figure 3 illustrates the effect of cement replacement on the water consistencies of cement blended with ESA and LBPA respectively between $0-10 \mathrm{wt} . \%$ at interval of $2.5 \mathrm{wt} . \%$. An increase in water consistencies of cement blended with LBPA and ESA were experienced as the cement replacement levels were increased. The water consistencies of binary blends were higher than the control ranging between $29.2-32.2 \%$ as 
against $29.0 \%(11.03 \%)$. A similar increase in the consistency of LBPA cement blend by $16.67 \%$ was observed by Iorshagher

et al. [28] as cement replacement from 0-30 wt.\%.

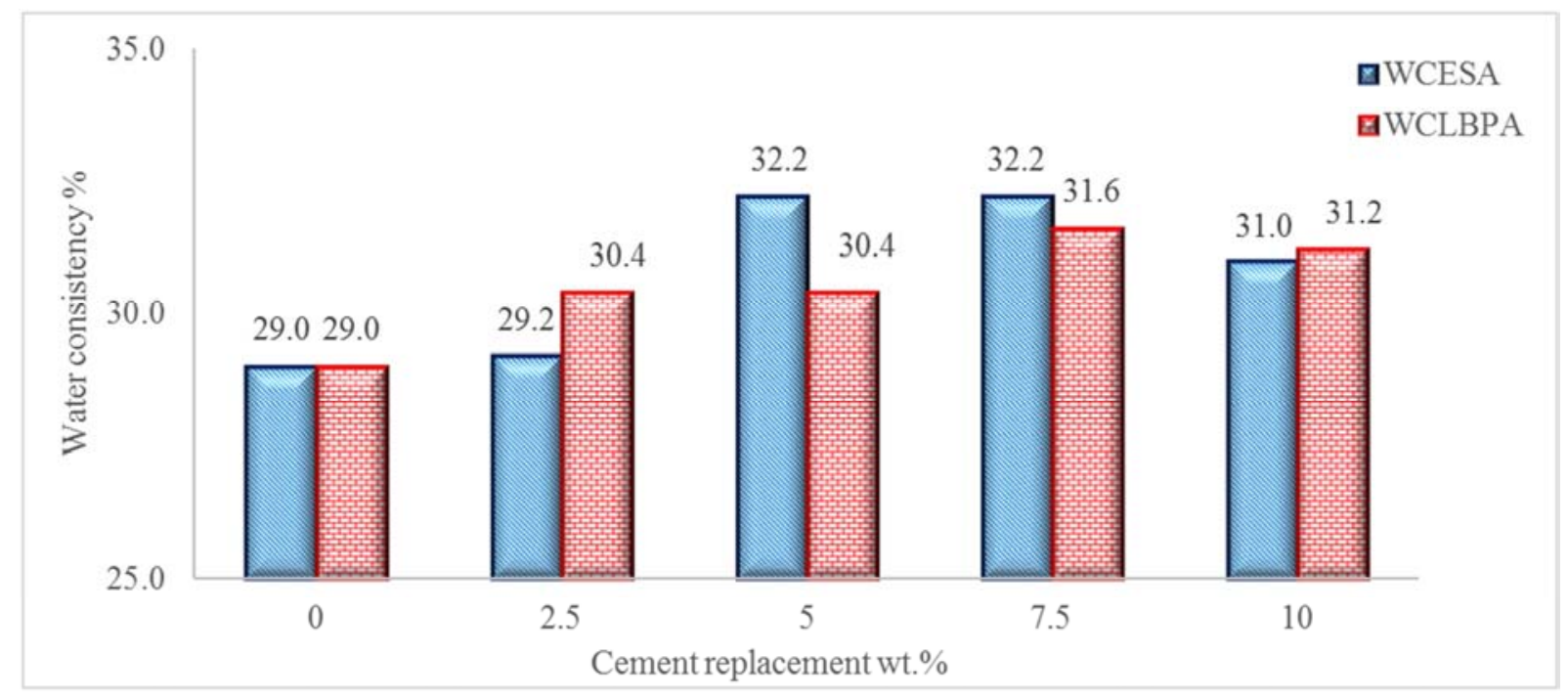

Figure 3. Variation of cement replacement on the consistency of binary cement blends.

This increase could either be attributed to the presence of unburnt carbon evident by the high LOI of their ashes or diminution of the $\mathrm{C}_{3} \mathrm{~S}$ in cement. Another reason is due to a narrower particle size distribution by the inclusion of the ashes resulting in increased consistencies. Sprung and Siebel [22] and Detwiler [31] indicated that the particle size distribution can considerably influence the water demand of cement blends.

Figure 4 illustrates the effect of replacing ESA with LBPA at LBPA/LBPA-ESA ratio from 0-1.0 at different cement replacements from $0-10 \mathrm{wt} . \%$ at intervals of $2.5 \mathrm{wt} . \%$. It could be seen that at $2.5 \mathrm{wt} . \%$ cement replacement as the ESA content was gradually replaced with LBPA, the water consistency of various cement blends increased in comparison with control. The cement blends experienced a variation in the consistency results as ESA was replaced by LBPA at various LBPA/LBPA-ESA ratios for cement replacements of 2.5, 5, 7.5 and $10 \mathrm{wt} \%$. The increase in the water consistency could be related to the unburnt carbon and porous nature of the ashes as well as the narrower particle size distribution of the cement blends resulting in higher consistency compared to control, while the decrease in the consistency could be linked with the wide particle size distribution due to the ashes inclusion at various proportions.

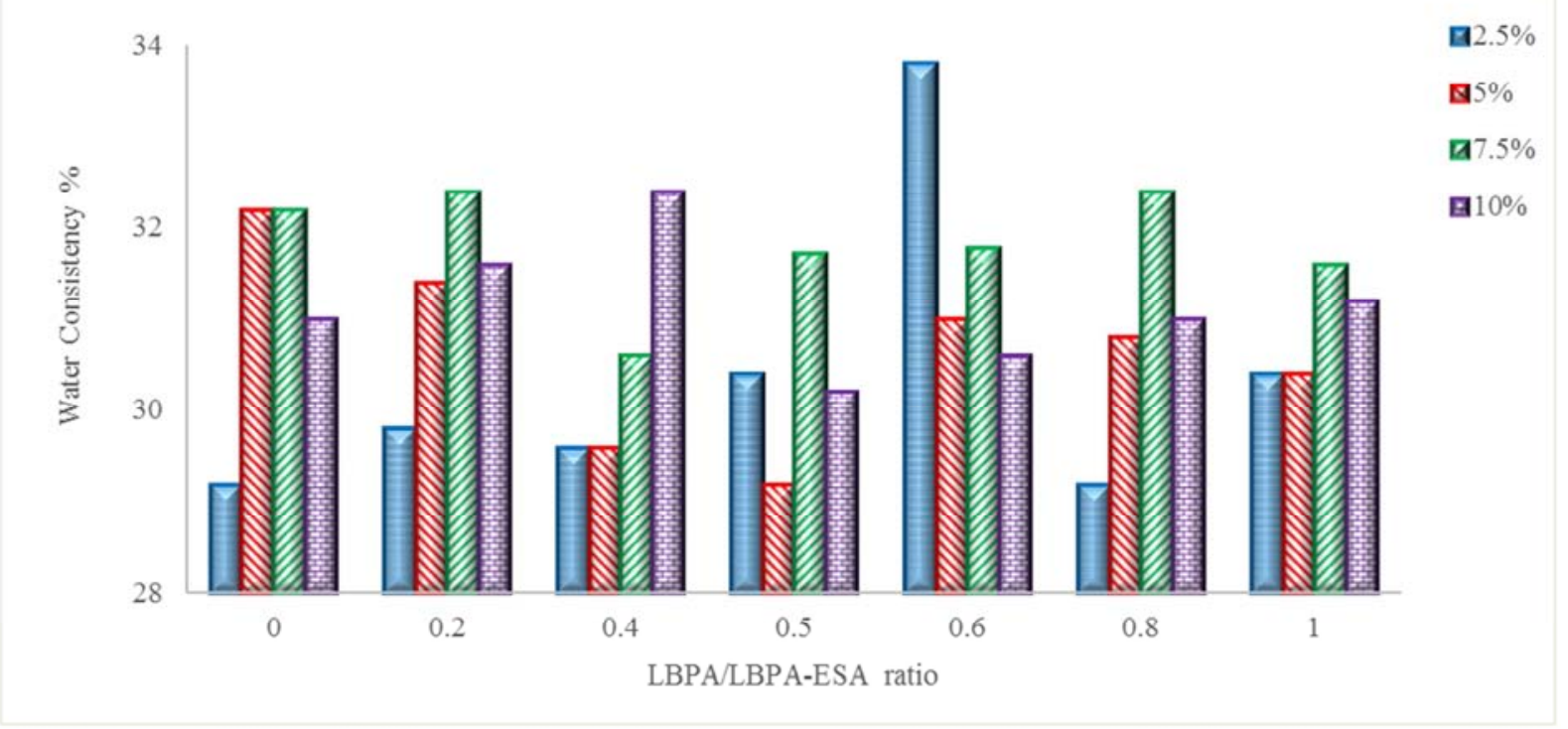

Figure 4. Variation in ash content on the water consistency of cement blends.

\subsection{Effect of Cement Replacement on the Setting Time of LBPA and ESA Cement Blends}

Figure 5 indicates the effect of cement replacement in wt.\% of ESA cement and LBPA cement blends independently from $0-10 \mathrm{wt} . \%$ at interval of $2.5 \mathrm{wt} . \%$ on the initial setting time of binary cements. The initial setting time of all ESA cement blends were found to be higher than those of LBPA cement 
blends for various cement replacements from 0-10 wt.\%. All cement blends experienced a retardation in their setting times with exception of 5 and $10 \mathrm{wt} \%$ LBPA cement blends respectively. All ESA cement blends experienced a retardation in their initial setting time followed by an acceleration as the ESA content was increased between 0-10 wt.\%, while LBPA cement blends indicated an elongation in their initial setting time with the exception of cement blends with 5 and $10 \mathrm{wt} . \%$ respectively. Whereas, LBPA cement blends showed a series of accelerations and retardations in its initial setting times as cement was gradually replaced with LBPA content from 2.5-10 wt.\%. Iorshagher et al. [28], Tangchirapat et al. [29] and Cordeiro et al. [30] observed retardations in both setting time of LBPA cement blends as LBPA content was increased and attributed the pattern to low hydration rate owing to LBPA slow pozzolanic reactivity. The retardations in the setting time of ESA cement blends and some LBPA cement blends could be attributed to unburnt carbon present evident by the high LOI and porous nature of the ashes. Thus, resulting in more water for consistency resulting in their retardations which is in agreement with Kaya [23] and Olubajo and Osha [24].

Similarly, the retardation in ESA cement blends in comparison with control could be attributed to the narrower particle size distribution caused by its inclusion, thereby retarding by between 23 and 114 minutes compared to control. Other reasons include elongation of the setting times of ESA and LBPA cement blends owing to diminution of clinker content as a result of cement replacement: the presence of $\mathrm{Mg}(\mathrm{OH})_{2}$ which provides a protective covering which in turn retards the hydration rate of cement blend with LBPA compared with control $[10,25]$. Similarly, the acceleration in the LBPA cement blends could be due to the available lime which assist in enhancing hydration rate.

Figure 6 indicated that at 2.5 wt.\% cement replacement, the final setting time of both LBPA and ESA cement blends both experienced an initial acceleration beyond which any further increase resulted in a retardation in the final setting time respectively. Fazeera et al. [9] experienced a similar acceleration (decrease) in the initial and final setting times of ESA cement blends as the amount of ESA was increased from $0-2$ wt. $\%$ and concluded that its inclusion accelerated its setting times could be attributed it to either physically filling of the pores between the cement particles or chemically due to the formation of carboaluminate which accelerates the setting time owing to formation of calcium hydroxide at the early age resulting from the provision of nuclei sites. Similarly, according to Olubajo et al. [7] and Bonavetti et al. [26], the accelerated setting time of the paste could be attributed to the reaction between tricalcium aluminate $\left(\mathrm{C}_{3} \mathrm{~A}\right)$ and lime/ limestone produces carboaluminate $\left(\mathrm{C}_{3} \mathrm{~A} . \mathrm{CaCO}_{3}\right)$, which decreases the rate of ettringite transformation to monosulfate. Whereas, the elongated setting times experienced could be tied to the consumption of lime during pozzolanic activity resulting in the reduction in available free lime which favors decrease in the rate of carboaluminate formation and ettringite transformation to monosulfate thus, resulting in an increase in the setting times [27].

Figures 7 and 8 illustrate the variation in the initial and final setting time results as ESA was gradually replaced with LBPA at various cement replacement level. It was observed from Figure 7, that cement replacement of 2.5 and $7.5 \mathrm{wt} . \%$ as ESA was gradually replaced with LBPA, the initial setting time experienced a series of accelerations and retardations while cement replacement of 5 and $10 \mathrm{wt} . \%$ experienced a series of accelerations and an elongation in its initial setting time. Generally, initially as the ESA was gradually replaced with LBPA for all replacements, resulted in an acceleration in its initial setting time followed by a series of retardations. The initial acceleration experienced could be attributed to the ESA content due to the formation of monosulfate at the expense of ettringite which leads to acceleration of the setting times while the presence of unburnt carbon in the ashes and the narrower particle size distribution could be responsible for the retardations $[9,10,26,27]$

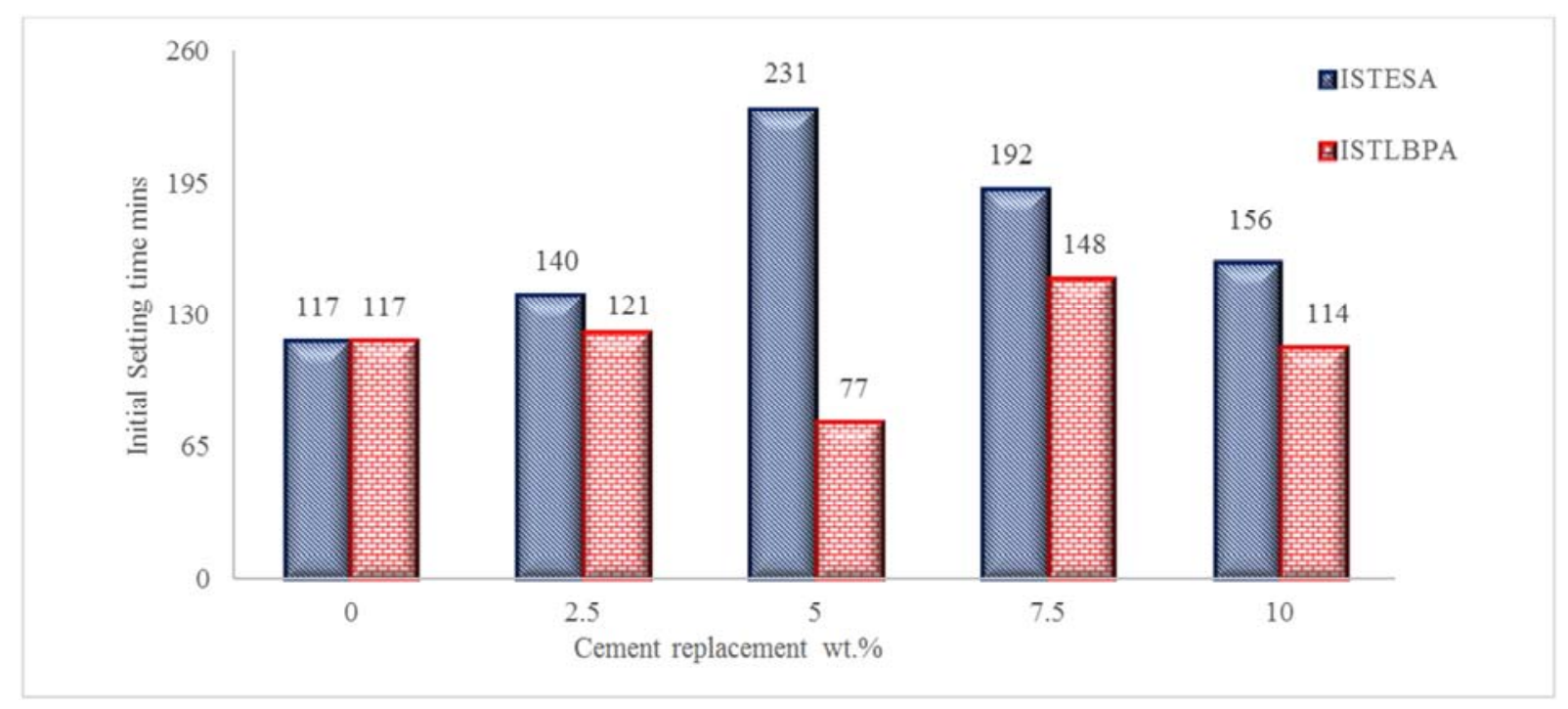

Figure 5. Variation in cement replacement on the initial setting time of binary cement blends. 


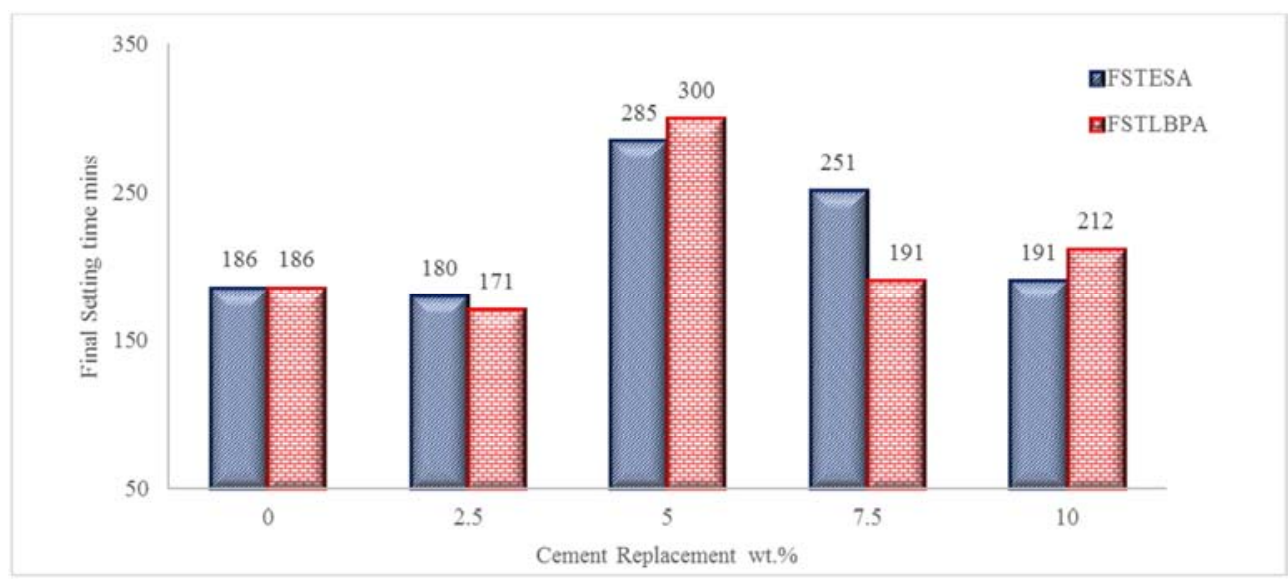

Figure 6. Variation in the cement replacement on the Final setting time of binary cement blends.

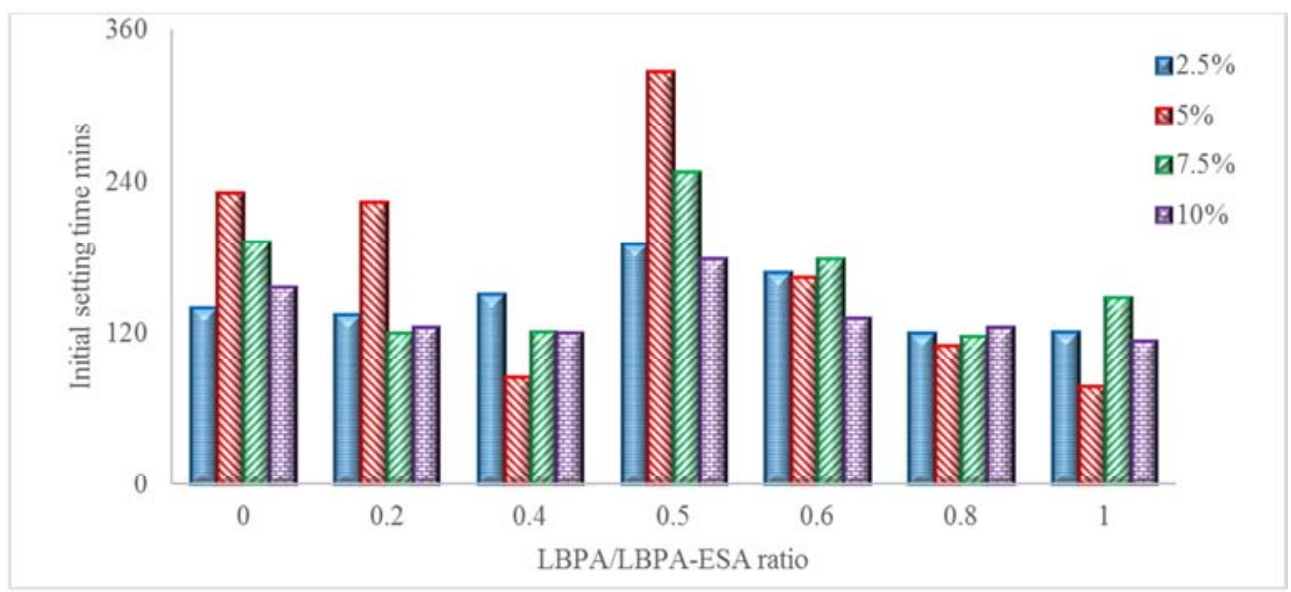

Figure 7. Replacement of ESA with LBPA content on the Initial setting time of cement.

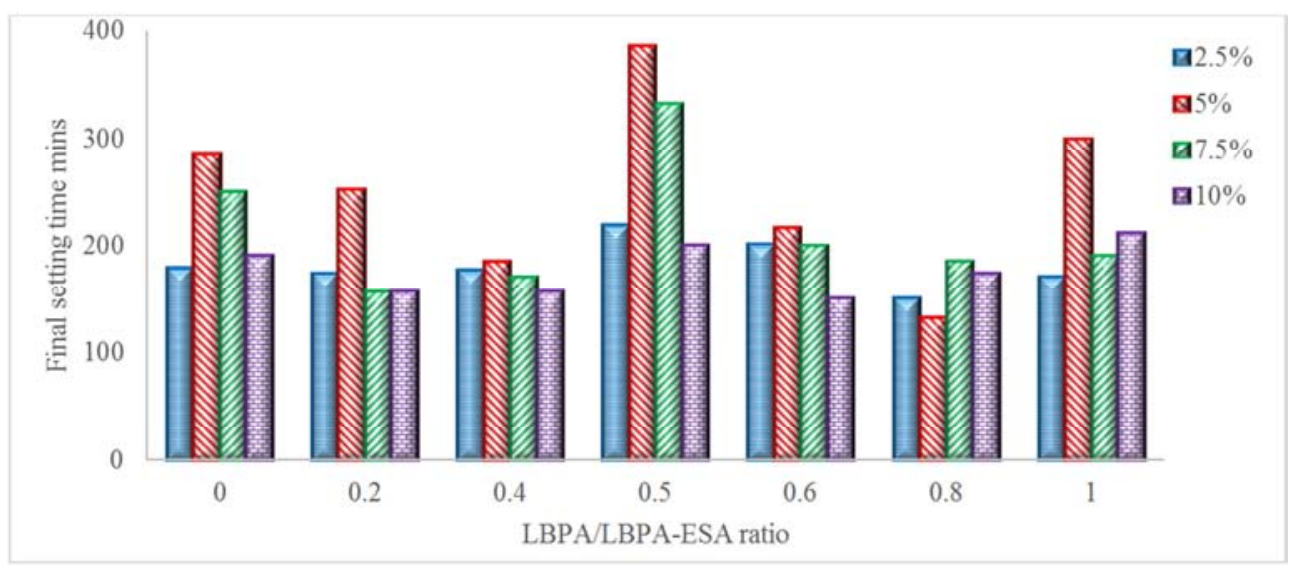

Figure 8. Replacement of ESA with LBPA content on the Final setting time of cement blends.

Figure 8 showed similar trends as ESA was gradually replaced with LBPA at various cement replacement level. It was also observed that all cement replacement indicated a series of accelerations and retardations as ESA was gradually replaced with LBPA in its final setting time.

\section{Conclusion}

The following conclusions were reached from research: Variations in the water consistencies of binary cements were experienced as the cement replacement level of the ashes were increased from $0-10 \mathrm{wt} . \%$ at various LBPA/LBPA-ESA ratios. The increase in their water consistencies could be attributed to the diminution of $\mathrm{C}_{3} \mathrm{~S}$ in cement, the unburnt carbon presence in the ashes coupled with the porous nature of LBPA and narrower particle size distributions of the blended cements while a decrease in their water consistencies could be linked with wider particle size distribution due to ashes inclusion.

The initial setting time of LBPA cement blends experienced a series of retardations and accelerations while ESA cement 
blends experienced a retardation followed by several accelerations as the cement replacement levels were increased from 0 - 10 wt.\%. All ESA cement blends, 2.5 wt. $\%$ and 5 wt. $\%$ LBPA cement blends experienced a retardation in their initial setting times in comparison with control whereas cement blended with 7.5 and 10 wt.\% LBPA underwent accelerations. The final setting time of ESA cement blend experienced a series of acceleration and retardations whereas, LBPA experienced a series of accelerations and retardations as the cement replacement levels were increased. The wider particle size distribution compared to control, the unburnt carbon presence in the ashes, the formation of $\mathrm{Mg}(\mathrm{OH})_{2}$ coupled with diminution of the clinker content could be reasons for the elongation of the setting time of ESA and LBPA cement blends. The acceleration of the setting time of LBPA cement blends could be due to the available lime which tends to accelerate the hydration rate.

As the ESA content was gradually replaced with LBPA at various cement replacement levels between $0-10$ wt.\% resulted in a variation in the both initial and final setting times (series of accelerations and retardations). The retardation in their setting times could be linked to the diminution of clinker content or formation of magnesium hydroxide, the presence of unburnt carbon in ashes while the acceleration of their setting times could be related to either a narrower particle size distribution of the cement blends or an interaction between tricalcium aluminate and limestone to favor ettringite at the expense of monosulfate.

\section{Acknowledgements}

The authors wish to thank Ashaka Cement Plc Nigeria and the Department of Chemical Engineering of Abubakar Tafawa Balewa University, Bauchi Nigeria for providing infrastructure, facilities and their support to this research work.

\section{References}

[1] Adejo, B. O., Ali, H., and Babatunde, R. I. (2019). Investigation of Locus Beans Waste Ash as Partial Replacement for Cement in Concrete Structures, International Journal of Scientific Research in Education, 12 (1), 144-150.

[2] Dave, N., Misra, A. K., Srivastava, A. and Kaushik, S. K. (2016) Setting time and standard consistency of quaternary binders: The influence of cementitious material addition and mixing, International Journal of Sustainable Built Environment. 1-7.

[3] Snelson D., Wild S., O'Farrel, M. (2011). Setting times of portland cement - metakaolin-fly ash blends. Journal of Civil Engineering and Management, 17 (1), 55-62.

[4] Aguwa, J. I., Alhaji, B., Jiya, A. and Kareem, D. H. (2016). Effectiveness of locust bean pod solution (LBPS) in the production of sandcrete blocks for buildings. Nigerian Journal of Technological Development, 13 (1), 13-16.

[5] Adama, A., and Jimoh, Y. (2012). Effect of locust bean pod ash on strength properties of weak soils. AU Journal of Technology, $16(1), 21-35$.
[6] De Weerdt, K., Kjellsen, K. O., Sellevold, E., and Justnes, H. (2011). Synergy between fly ash and limestone powder in ternary cements. Cement and Concrete Composites, 33 (1), 3038. doi: 10.1016/j.cemconcomp.2010.09.006.

[7] Olubajo, O. O, Isa, Y. M., Ayeni, S., Menta, S. and Nwuhu, W. (2020). A study on ordinary portland cement blended with rice husk ash and metakaolin Path of Science. 6 (1), 3001-3019. Available on website link: http://www.pos.org.

[8] Utsev, J. T. and Taku, J. K. (2012). Coconut shell ash as partial replacement of ordinary portland cement in concrete production, International Journal of Scientific \& Technology Research, 1 (8), 86-89.

[9] Fazeera, U., Kamaran, S., and Yasmin, H. (2016). Viability of eggshells ash affecting the setting time of cement, International Journal of Civil, Environmental, Structural, Construction and Architectural Engineering 10 (3), 103-107.

[10] Olubajo, O. O., Abubakar, J. and Osha, O. A. (2020b). The effect of eggshell ash and locust bean pod ash on the compressive strength of ternary cement, Path of Science, 6 (3), 4001-4016. Available on website link: http://www.pos.org.

[11] Akpenpuun, T. D., Akinyemi, B. A., Olawale, O., Aladegboye, O. J., and Adesina, O. I. (2019). Physical, mechanical and microstructural characteristics of cement-locust bean pod ash mortar blend. Journal of Applied Sciences and Environmental Management, 23 (3), 377. doi: 10.4314/jasem.v23i3.1.

[12] Kumar, P., Vishwakarma, A., and Soni, K. (2016). Laboratory analysis of cement concrete prepared with egg shells ash. International Journal of Advanced Technology for Science \& Engineering Research, 1 (6), 16-23.

[13] Balamurugan, M., and Santhosh, R. (2017). Influence of egg shell ash on the properties of cement. Imperial Journal of Interdisciplinary Research, 3 (4), 160-165.

[14] Mtallib, M., and Rabiu, A. (2009). Effects of eggshells ash (ESA) on the setting time of cement. Nigerian Journal of Technology, 28 (2), 29-38.

[15] BS 12 (1991). Specification for portland cement, British Standard Institution.

[16] NIS 444-1: 2003. Composition, specification and conformity criteria for common cements. Standards Organization of Nigeria.

[17] Indian Standard codes of practice for consistency test IS 4031 (1968), Bureau of Indian Standards, New Delhi.

[18] BS 4550-3-3.6 Methods of testing cement. Physical tests. Test for setting times.

[19] Indian Standard codes of practice for initial and final setting time of cement IS 4031 (1968), Bureau of Indian Standards, New Delhi.

[20] ASTM C618-12a (1999). Standard specification for coal fly ash and raw or calcined natural pozzolan for use in concrete. ASTM International, West Conshohocken, PA, USA, p5.

[21] Ikumapayi, C. M., (2016) Crystal and microstructure analysis of pozzolanic properties of bamboo leaf ash and locust beans pod ash blended cement concrete. Journal of Applied Science and Environmental Management JASEM, 20 (4), 943-952. 
[22] Sprung, S., and Siebel, E. (1991). Assessment of the suitability of limestone for producing portland limestone cement. $Z K G$ International, Edition B, 44 (1), 1-11.

[23] Kaya, A. (2010, September). A study on blended bottom ash cements (Master's thesis). Retrieved from http://etd.lib.metu.edu.tr/upload/12612504/index.pdf.

[24] Olubajo, O., and Osha, O. (2013). Influence of bottom ash and limestone powder on the properties of ternary cement and mortar. International Journal of Engineering Research and Technology, 2 (7), 1201-1212.

[25] Venkateswara, R., Kontham, G., Venkata, R., and Chundupalli, S. (2011). Effect of potassium chloride $(\mathrm{KCl})$ on ordinary portland cement (OPC) concrete. Research Journal of Chemical Sciences, 1 (2), 103-107.

[26] Bonavetti, V., Rahhal, V., and Irassar, E., (2001). Studies on the carboaluminate formation in limestone filler-blended cements. Cement and Concrete Research, 31 (6), 853-859. doi: 10.1016/s0008-8846(01)00491-4.

[27] Heikal, M., El-Didamony, H., and Morsy, M. S. (2000).
Limestone-filled pozzolanic cement, Cement and Concrete Research, 30, 1827-183.

[28] Iorshagher, A. S., Ocholi, A., Hassan, U. (2019). Properties of concrete using limestone dust and locust bean pod ash. Master Progress Seminar. Ahmadu Bello University, Zaria.

[29] Tangchirapat, W., Jaturapitakkul, C., and Chindaprasirt, P. (2009). Use of palm oil fuel ash as a supplementary cementitious material for producing high-strength concrete. Construction and Building Materials, 23 (7), 2641-2646.

[30] Cordeiro, G. C., Toledo, F., R. D., Tavares, L. M., and Fairbairn, E. M. R. (2012). Experimental characterization of binary and ternary blended-cement concretes containing ultrafine residual rice husk and sugar cane bagasse ashes. Construction and Building Materials, 29, 641-646.

[31] Detwiler, R. J. (1995). Effects on cement of high efficiency separators, Research and Development Bulletin RD110T, Portland Cement Association, Skokie, Illinois. 